\title{
Adoption of climate change friendly New Rice for Africa (NERICA) varieties among farmers in Mwea West Sub-county, Kenya
}

\author{
Benson Kamau Mburu* and Christine Wanjiku Ngucia \\ Department of Environmental Science and Education, Kenyatta University, Kenya.
}

Received 29 October, 2021; Accepted 11 January, 2022

\begin{abstract}
Climate change and inefficient water utilization have led to marked fluctuations of the mean rice crop production in sub-Sahara Africa. In order to improve food security and households' income, adaptation strategies to climate change such as the adoption of new rice varieties are inevitable. This study examined the farmers' perception and adoption of climate change friendly New Rice for Africa in Mwea West Sub-county. The study applied the descriptive survey design with questionnaires being administered to a sample of $\mathbf{3 7 6}$ farmers. Key informants included four officers from Mwea Irrigation Agricultural Development and the Ministry of Agriculture. Quantitative data were analysed using Statistical Package for Social Sciences whereas qualitative data were analysed through establishing the categories and themes, relationships/patterns, and conclusions drawn in line with the study objectives. Results indicated a highly significant difference in adoption between farmers affiliated to Mwea Irrigation Scheme and the out-growers $\left(X^{2}=18.5\right.$, df $\left.=2, p=1.67 \times 10^{-6}\right)$. The study concluded that the adoption of New Rice for Africa varieties in the Mwea West Sub-county is low and slow. This is mainly caused by inadequate information among the farmers as well as low market demand for the rice varieties. There is a need to enhance these rice varieties by intensifying efforts to sensitize farmers.
\end{abstract}

Key words: Climate change, new rice for Africa, adaptation strategies.

\section{INTRODUCTION}

Climate change is defined by IPCC (2007) as "a change in the state of average weather patterns attributed to both human and natural induced factors and which in addition to variability persists over long periods." According to Speranza (2010), climate change and variability has resulted in variations in temperature, rainfall patterns, and wind direction in many parts of the world. Kenya is one of the countries that have experienced serious climate change and variability. The country is already experiencing rising temperatures, erratic rainfall, increased frequency of torrential rainfall, melting and retreat of mountain glaciers, and occurrence of drought and floods (Ndiritu, 2013). Major droughts in Kenya occur every decade and their impacts are felt by the already high population and more so by the less resilient and ecologically fragile arid and semi-arid lands. This calls for intense food security measures that will help feed millions of Kenyans who continue to face severe to acute food

${ }^{*}$ Corresponding author. E-mail: mburu.benson@ku.ac.ke.

Author(s) agree that this article remain permanently open access under the terms of the Creative Commons Attribution License 4.0 International License 
insecurity (USAID, 2017a).

Rice is a significant crop in Africa, both for food security and commerce (Manneh et al., 2007). Though domestic rice production has gone up in Africa in the recent past, it has not matched with the demand. There is a need to achieve necessary adaptation to the effects of climate change (severe temperatures, numerous flooding, droughts, and high salinity of water used for irrigation) which negatively affect production to bridge the demand gap. According to United States Department of Agriculture (2017), rice imports in sub Saharan Africa will grow from 12.3 million tons in 2017 to 15.4 million by 2026. These imports are expected to exceed those of Asia, making sub-Saharan Africa to become the leading destination in the global rice trade.

Rice cultivation has helped Kenya to cope with food insecurity and is rated as the country's third staple food after maize and wheat. National rice consumption is estimated at 550,000 metric tonnes whereas the country produces only 150,000 metric tonnes of rice every year (Atera et al., 2018). The shortfall is made up through rice importation. The low production is attributed to poor water management, drought, late maturity and poor adaptability of new varieties, floods, pests and diseases, poor seed delivery systems, limited national breeding capacities, weeds, soil infertility, soil salinity and iron toxicity, lodging, high cost of production and erratic weather patterns (Olembo et al., 2010). This deficit in the supply of rice has led to a continuous increase in rice prices.

The New Rice for Africa (NERICA) is bred from African rice (Oryza glaberrima) and Asian rice (Oryza sativa) developed through the effort of the West African Rice Development Association (WARDA)/Africa Rice Center (Olembo et al., 2010). There are two types of NERICA varieties: upland NERICAs and lowland NERICAs adapted for either rain-fed or irrigated environments. In total, there are now 82 NERICA varieties - 18 uplands, 60 rainfed lowland and 4 irrigated varieties (Africa Rice Centre, 2020). The NERICA varieties for various rice ecologies are a significant international public good.

The varieties commonly planted in Kenya are NERICA $1,4,10$ and 11 . The upland varieties can grow without flooding and thus are water efficient. The varieties are also blast tolerant, resistant to logging, tolerant to soil acidity and iron toxicity, early maturing, and high yielding compared to both parents (JICA, 2006). To improve food security, households' income and reduce importation of rice, the adoption of new rice varieties such as NERICA is unavoidable. The annual rice consumption in Kenya is increasing at a higher rate compared to wheat and maize (Atera et al., 2018). On the other hand, rice yield in Mwea declined from 6.6 tonnes/ha in the 1970s to 4.0 tonnes/ha in the 1990s (Wanjogu et al., 1995). Overall, rice yield in Kenya recorded a decline from 5.91 tonnes/ha in 1963 to 3.98 tonnes/ha in year 2000 (Kuria, 2004).

Studies have shown that there is a distinct flux of the mean rice crop production which has been attributed to poor water utilization and other climatic factors in Kenya (Nyamai et al., 2012). According to Hussain et al. (2020), nearly $51 \%$ of rice cultivation and production would be reduced in the ensuing century as a result of global climate change. The promotion of rice under global climate change thus remains a major challenge necessitating the development of the National Rice Development Strategy (NRDS) to promote rice production and curb food insecurity. The National Rice Development Strategy (2008-2018) reckons that to enhance water use efficiency and environmental conservation in the production of rice, there should be a drift towards upland rice production (MoA, 2009). FAO (2012) on the other hand notes that in order to realize food security for the increasing population and mitigate the effects of climate change there is a necessity to transform agriculture without further degrading the natural resource base.

The adoption of NERICA varieties though in a limited way has extended to parts of Uganda where it has become quite famous among some farmers making them abandon tobacco which is one of the country's largest cash crops (Kijima et al., 2007). This has seen rice production in these areas greatly increased. However, a study conducted by Diagne et al. (2010) to determine the adoption level of NERICA and its determinants in rural Uganda, three years after it was introduced, found the adoption level to be only $4 \%$. The government of Kenya has put in efforts to popularise NERICA varieties through the provision of seeds to farmers. However, most irrigation schemes in the country have not yet embraced the NERICA varieties (Abuje, 2013). Diagne (2006) observed that the high-yielding attribute of NERICA varieties does not guarantee high adoption rates as other factors such as poverty hinder its adoption.

Since NERICA varieties adaptability trials in Kenya began in the year 2003, and successful field demonstrations were done, very little information is available concerning its awareness and adoption. It is on this basis that this study was carried out to assess the farmer's perception and adoption of NERICA varieties including the factors influencing its adoption among farmers in Mwea West Sub-county, Kenya.

\section{MATERIALS AND METHODS}

\section{Study area}

The study was conducted in the Mwea West Sub-county which is in Kirinyaga County (Figure 1). The area is located between latitudes $0^{\circ} 32^{\prime} \mathrm{S}$ and $0^{\circ} 46^{\prime} \mathrm{S}$ and longitudes $37^{\circ} 13^{\prime} \mathrm{E}$ and $37^{\circ} 30^{\prime} \mathrm{E}$, (Nyamai et al., 2012). The diurnal temperature ranges between 15 and $30^{\circ} \mathrm{C}$ while annual rainfall ranges between 356 and $1626 \mathrm{~mm}$ with an average of $950 \mathrm{~mm}$ (MoA, 2008). The rainfall is erratic with a bimodal distribution.

Mwea West Sub-county has different types of soils. Most of the area is covered by black cotton soils intercepted by other clay soils. There are sheets of sandy and silty soils as a result of run-offs here and there. The main types of vegetation are crops such as rice 


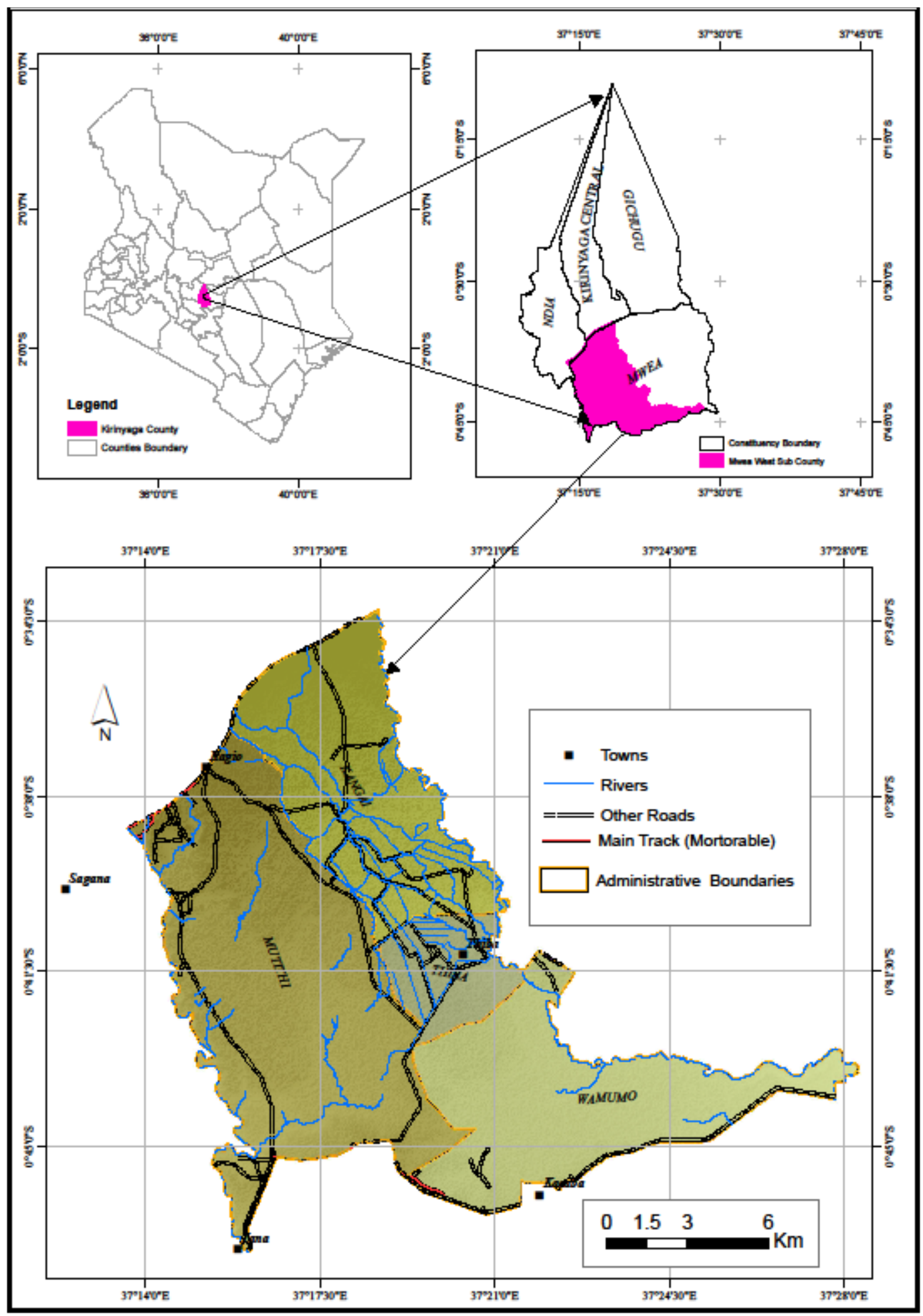

Figure 1. Map of the Study Area.

Source: Directorate of Resource Survey and Remote Sensing, Kenya.

which is mainly grown in paddies and horticultural crops such as tomatoes and French beans which are primarily grown under irrigated conditions (GoK, 2013). The area exhibits two types of settlements; clustered settlements around Kagio urban centre and scattered settlements occupying the lower arid parts of Mwea (GoK, 2013).

The rice farming scheme has a total area of 30,350 acres out of which about 15,000 acres have been developed for paddy rice 
production. The scheme is divided into five sections namely Tebere, Nguka, Thiba, Wamumu, and Karaba with an average area of 3,000 acres each. It supports approximately 3,242 farm families living in 36 villages (GoK, 2013). All the land is held in trust by Kirinyaga County Government and the National Irrigation Board (NIB). Farmers are given licenses to till the land which can be passed to their children (NIB, 2012).

The study targeted rice farmers in two Assembly Wards (Thiba and Mutithi) in Mwea West Sub-county. These two wards have a population of 67,964 persons represented in 19,648 households (KNBS, 2009). The farmers comprised of those under the Mwea Irrigation Scheme as well as out-growers. The study also targeted key informants from MIAD and the Ministry of Agriculture such as Agricultural Extension Officers and experts who are involved in research and dissemination of rice varieties.

\section{Sample size and sampling procedure}

The sample size was determined using the Krejcie and Morgan (1970) published table. The sampling unit was the household and a population of 19,648 households gave a sample size of 376 households. The farmers were stratified into out-growers and those under Mwea Irrigation Scheme. One hundred and eighty-eight respondents were selected using purposive sampling in each stratum. Both adopters (respondents who had adopted NERICA) and non-adopters (respondents who had not adopted NERICA) in each stratum were sampled. A total of four experts from MIAD and the Ministry of Agriculture were also purposively sampled to focus on the ones involved in the dissemination of NERICA.

\section{Data collection instruments}

Robert (2013) suggested that the research instruments used should remove any subjectivity that may be introduced in course of getting data. The study involved both primary and secondary sources of data. The instruments used to collect primary data included questionnaires and interview schedules. Secondary data was obtained from a wide range of sources ranging from published and non-published sources such as books, journals, and the internet. The combination of these instruments and sources ensured that the data collected was comparative and more precise. These tools barred the alteration of judgment based on a unilateral source of facts and figures.

\section{Data analysis methods}

Quantitative data were analysed using the Statistical Package for Social Sciences (SPSS). Qualitative data were analysed thematically to obtain useful conclusions and recommendations. Descriptive and inferential statistical analyses were done. Two measures of central tendency (mean and median) and two measures of dispersion (Variance and standard deviation) were also obtained. On the other hand, for inferential and comparative purposes, correlation analysis and chi tests were used to compare the information from farmers in the MIS and out-growers.

\section{RESULTS AND DISCUSSION}

\section{Perception about NERICA varieties among farmers in Mwea West Sub-county}

The study showed that $30.32 \%$ of the respondents agreed to the statement that most farmers were aware of NERICA varieties (Figure 2). However, the majority $(59.04 \%)$ of the respondents disagreed with the statement while $10.64 \%$ were uncertain.

These results indicated that the farmers' level of awareness about NERICA rice varieties in the study area was low. However, many farmers noted that they had only heard about NERICA but had inadequate information about its management and benefits. Thus, the low level of information regarding NERICA in the Mwea West Sub-county contributed to its low adoption. This corresponds to findings by Olembo et al. (2010) which showed that before farmers adopt new agricultural technologies, they first seek information on (among other factors) water requirements, demand, the technology needed, maturity, high yields, and production cost. Lack of information was also noted as a limiting factor to devising adaptation strategies by small-scale farmers in Yatta District by Mburu et al. (2015).

Several socioeconomic characteristics were found to be important determinants of NERICA awareness and adoption among the farmers. These included but were not limited to age, major occupation, gender, years of experience, and training. These results further corroborate the findings of a study done by Nguezet et al. (2012) which revealed that people will adopt various farming practices based on awareness.

\section{Farmers' affiliation and rate of NERICA adoption}

The study established that only $19.68 \%$ of all out-growers adopted growing NERICA varieties (Table 1). On the other hand, only $31.38 \%$ of the farmers under MIS adopted NERICA. Overall, $74 \%$ of all the farmers (MIS and out-growers) in the Mwea West Sub-county had not adopted NERICA.

Drawing comparisons from the findings, it was clear that those farmers under MIS were better adopters than the out-growers. Indeed there was a highly significant difference in adoption of NERICA between out-growers and farmers in MIS $\left(X^{2}=18.5, \mathrm{df}=2, \mathrm{p}=1.67 \times 10^{-6}\right)$. This could be attributed to information facilitation by the scheme through extension services. These findings corroborate the findings by Muchiri (2013) which established that farmers in the MIS were better adopters of new agricultural technologies since they could easily get extension services, training, seeds, and the necessary assistance in their farms.

\section{Factors influencing adoption of NERICA by farmers in Mwea West Sub-county}

The study found that 99.47 and $98.67 \%$ of the respondents felt that water crisis and seasonal trends are the major factors influencing adoption of NERICA 


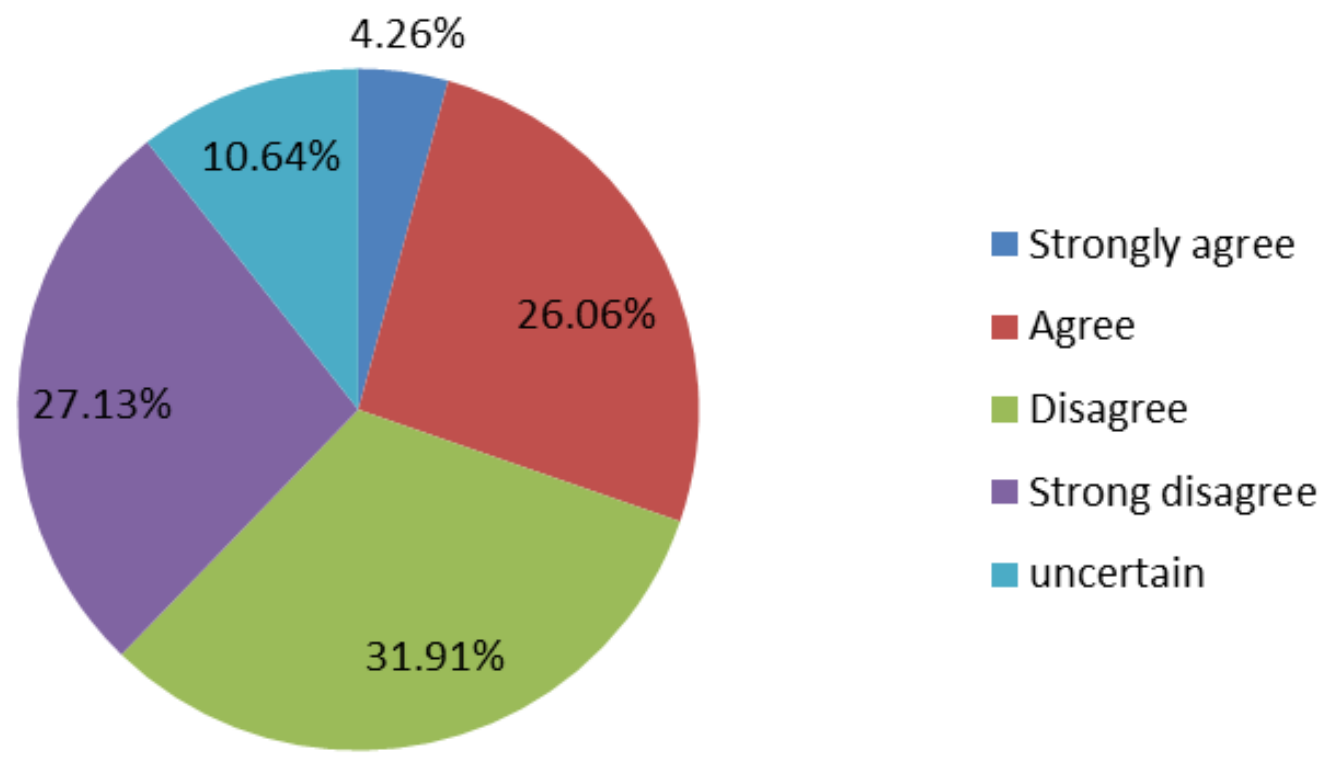

Figure 2. Perception about NERICA varieties among Mwea West Sub-county farmers.

Table 1. Farmers' affiliation and NERICA adoption by farmers in Mwea West Sub-county.

\begin{tabular}{lcccc}
\hline Farmer Affiliation & Adopted NERICA & Not Adopted NERICA & Totals & $\%$ \\
\hline Out-grower & $37(19.68 \%)$ & $151(80.32 \%)$ & 188 & 50 \\
MIS & $59(31.38 \%)$ & $129(68.62 \%)$ & 188 & 50 \\
Total & $\mathbf{9 6 ( 2 6 \% )}$ & $\mathbf{2 8 0}(\mathbf{7 4} \%)$ & $\mathbf{3 7 6}$ & $\mathbf{1 0 0}$ \\
\hline
\end{tabular}

Table 2. Factors influencing farmers' choice of NERICA in Mwea West Sub-county.

\begin{tabular}{lcc}
\hline Factor & Frequency & $\%$ \\
\hline Water crisis & 374 & 99.47 \\
Market forces & 69 & 18.35 \\
Low cost of production & 287 & 76.33 \\
Awareness & 314 & 83.51 \\
Government intervention & 153 & 40.69 \\
Seasonal changes & 371 & 98.67 \\
Maturity duration & 365 & 98.07 \\
High yields & 278 & 73.94 \\
Influence from other farmers & 64 & 17.02 \\
\hline
\end{tabular}

varieties respectively (Table 2 ). The farmers felt that there was little information regarding the continuous fluctuations in the rainfall trends in Mwea West Subcounty. This is closely linked to the water crisis which is a critical factor in irrigated rice growing. Other key factors influencing the adoption of NERICA varieties included: duration of maturation $(98.07 \%)$ and awareness $(83.51 \%)$. Other influencing factors were low cost of production, high yields, government intervention through provision of seeds, market forces, and other people's influence.

These findings are in agreement with those by Uwaegbuonu (2010) which indicated that awareness of any technology and upcoming farming practice is crucial in determining if individuals will adopt it or not. Farmers were aware of the existence of NERICA but lacked the necessary information and knowledge required about seed treatment, land preparation, pest, and disease 
Table 3. Challenges faced by NERICA farmers in Mwea West Sub-county ( $N=96)$.

\begin{tabular}{lcc}
\hline Challenges in the cultivation of NERICA & Frequency & Percentage \\
\hline Low yields & 75 & 78 \\
Difficulty in threshing & 64 & 67 \\
Low demand & 93 & 97 \\
Poor climatic conditions & 69 & 72 \\
Informational crisis & 81 & 84 \\
Lack of seeds & 66 & 69 \\
\hline
\end{tabular}

Table 4. Strategies that can spur NERICA rice adoption in Mwea West Sub-county.

\begin{tabular}{lcc}
\hline Strategies for the adoption of NERICA & Frequency & Percentage \\
\hline Training farmers & 356 & 95 \\
Ensure seed availability & 353 & 94 \\
Marketing strategies & 312 & 83 \\
Field demonstrations & 289 & 63 \\
Technological advancements & 238 & 75 \\
\hline
\end{tabular}

control among other key aspects associated with the propagation of NERICA. A study conducted in Nigeria funded by the Gatsby Foundation notes that; "although farmers who have access to and have adopted NERICA varieties are deriving higher yields and income, those who do not have regular access to seeds have abandoned NERICA lines in favour of low yielding local varieties" (Spencer and Leisel, 2012). This is also a reason why farmers in Mwea West Sub-county are reluctant to cultivate NERICA. Seeds have not been readily available to all farmers in the Agrovet outlets near them. The main supplier of the seeds is the Ministry of Agriculture and thus most of the farmers find it difficult to go for the seeds and opts for the readily available ones.

\section{Challenges to adoption of NERICA by farmers in Mwea West Sub-county}

The results showed that out of the 96 households that had adopted cultivation of NERICA in Mwea West Subcounty, the majority $(97 \%)$ had a challenge of the produce having low demand in the market (Table 3). $82 \%$ of the adopters lacked the necessary information needed to cultivate NERICA successfully from planting to harvesting whereas $78 \%$ had a challenge of low yields from the variety. Poor and unpredictable climatic conditions also proved to be a challenge to the farmers who felt that erratic rainfall patterns had affected the adoption of NERICA varieties in the Mwea West Subcounty. This agrees with the UNFCCC (2006) report which indicated that cyclical and erratic movements in rainfall and temperatures in many parts of the world lead to high crop failures amongst many households.
Although earlier research by Abuje (2013) and Dibba (2013) had shown that NERICA exhibits high yields characteristics, farmers in Mwea West Sub-county lacked the necessary know-how or approaches to ensuring high yields from NERICA. Apart from low yields and poor markets, the study further established that NERICA farmers had difficulties in threshing the rice and accessing seeds. According to Braun and Herstatt (2009), technology must be compatible, have some relative advantage, simple to apply and capable of future changes and accommodation of future technologies. Therefore, individuals will tend to discontinue those technologies, which have no value addition even after implementation.

Although NERICA varieties have high yielding rates comparatively, it is not a guarantee that there will be high adoption rates. Studies by Diagne et al. (2010), Yanagihara et al. (2011) and Tuong (2009) have shown that other underlying factors have discouraged the adoption of NERICA rice amongst many farmers including poverty. Farmers will always tend to plant what has high demand in the market and as such the government must work harder to popularise NERICA in Kenya.

\section{Strategies to improve adoption of NERICA in Mwea West Sub-county}

The farmers in Mwea West Sub-county felt that various strategies can be employed to improve the adoption of NERICA. 95\% of the respondents noted that training farmers is paramount to improving adoption (Table 4).

As noted earlier, NERICA varieties adaptability trials in 
Kenya began in the year 2003 and successful field demonstrations were done. However, there was inadequate information about its management and benefits. This emphasizes the fact that before farmers adopt new agricultural technologies, they first seek information. An equal number of farmers also felt that NERICA seeds should be made more readily available in the local agro vet shops as opposed to the current situation where only the Ministry of Agriculture distributes them.

Other strategies highlighted by the farmers include advancement in technology and marketing. The Kenyan rice market is heavily dominated by Pishori variety and a lot needs to be done to ensure NERICA penetrates the market. Most consumers go for Pishori rice in Kenya increasing its demand and market (Muchiri, 2013). NERICA is not famous among many farmers mainly due to competition from these pre-existing varieties like Pishori, BW IR, and ITA which have gained market and are in high demand. These results corroborate the findings by Kijima and Sserunkuuma (2013) that suggested that NERICA rice cultivation requires a strategic approach to ensure that farmers are aware and prepared to adopt the varieties in Sub-Saharan Africa.

\section{Conclusion}

Despite the efforts that have been put in place to popularize NERICA varieties by the Kenyan government and JICA, its adoption as an adaptation strategy to climate change is low and slow in Mwea West Subcounty. This is mainly caused by inadequate information among the farmers as well as low market demand of NERICA as experienced by those who already had cultivated the variety. The availability of seeds also posed a major problem to the farmers since they were not readily available especially for out-growers who opted to plant those varieties of rice whose seeds were readily available. Farmers in Mwea West Sub-county lacked enough technology to apply in their farming practices to ensure that the cultivation of NERICA was successful and beneficial for them.

On the other hand, those farmers affiliated with Mwea Irrigation Scheme were slightly better adopters of NERICA compared to out-growers. The farmers were keen to adopt rice varieties that would take minimum time to mature and help them cope with problems of water scarcity during dry seasons. Thus, given the right information, most farmers would adopt NERICA since it takes lesser time to cultivate and harvest.

\section{RECOMMENDATIONS}

Based on the findings of this research, there is a need to sensitize the farmers' regularly on climate change and the strategies that could be employed to curb the dangers associated with the change in Mwea West Sub-county. The government should also intensify programs to educate farmers on NERICA with regard to requirements, land preparation, seed treatment, and better technologies of farming. Information regarding the benefits of planting NERICA should also be passed on to the rice farmers through agricultural extension officers, Non Governmental Organisations and Community Based Organisations. This should be accompanied by thorough marketing strategies by the central and county governments to popularise NERICA. The central and county governments could also consider offering material incentives such as free seeds to the farmers.

\section{CONFLICT OF INTERESTS}

The authors have not declared any conflict of interests.

\section{ACKNOWLEDGEMENT}

The authors highly appreciate the participation of Mwea West Sub-county rice farmers and Mwea Irrigation Agricultural Development and Ministry of Agriculture officials.

\section{REFERENCES}

Abuje $\mathrm{J}$ (2013). Kenyan rice farmers yet to embrace NERICA variety. Africa Science.

Africa Rice Centre (2020). AfricaRice Daily - Newsletter. https://www.africarice.org/nerica

Atera EA, Onyancha FN, Majiwa EBO (2018). Production and marketing of rice in Kenya: Challenges and opportunities. Journal of Development and Agricultural Economics 10(3):64-70. http://www.academicjournals.org/JDAE

Braun V, Herstatt C (2009). User-innovation: Barriers to democratization and IP licensing. New York: Routledge.

Diagne A (2006). Diffusion and adoption of NERICA rice varieties in Côte D'ivoire. The Developing Economies 44(2):208-231. doi:10.1111/j.1746-049.2006.00014.x

Diagne A, Mindingoyi S, Wopereis M, Akintayo I (2010). The NERICA success story: development, achievements and lessons learned. Benin: The Africa Rice Center (Africa Rice).

Dibba L (2013). Estimation of NERICA adoption rates and impact: Estimation of NERICA adoption rates and impact on productivity and poverty of small-scale rice farmers in the Gambia. Saarbrucken: LAP LAMBERT Academic Publishing.

Food and Agriculture Organization of the United Nations (FAO) (2012). Action plan of the global strategy to improve agricultural and rural statistics: For food security, sustainable agriculture and rural development. Rome.

GoK (2013). Kirinyaga County Integrated Development Plan.

Hussain S, Huang Jie, Huang Jing, Ahmad S, Nanda S, Anwar S, Shakoor A, Zhu C, Zhu L, Cao X, Jin Q, Zhang J (2020). Rice Production under climate change: Adaptations and Mitigating Strategies. Springer Nature Switzerland AG 2020 S. Fahad et al. (eds.), Environment, Climate, Plant and Vegetation Growth https://doi.org/10.1007/978-3-030-49732-3_26

Intergovernmental Panel on Climate Change (IPCC) (2007). Climate Change 2007: Synthesis Report: Contribution of Working Groups I, II and III to the Fourth Assessment Report of the IPCC. Geneva. Switzerland. 
Japan International Cooperation Agency (JICA) (2006). JICA Kenya Newsletter. Nairobi: Japan International Cooperation Agency.

Kijima Y, Otsuka K, Sserunkuuma D (2007). Assessing the impact of NERICA on income and poverty in Central and Western Uganda. The journal of the International Association of Agricultural Economics pp. 327-337.

Kijima Y, Sserunkuuma D (2013). The adoption of NERICA rice varieties at the initial stage of the diffusion process in Uganda. African Journal of Agricultural and Resource Economics 8(1):45-56.

KNBS (2009). Kenya Population and Housing Census, 2009. Volume 1A. KNBS. Nairobi.

Krejcie RV, Morgan DW (1970). Determining sample size for research activities. Educational and Psychological Measurement 30(3):607610.

Kuria JN (2004). An economic analysis of rice production in Mwea Irrigation Scheme (Doctoral dissertation).

Manneh B, Kiepe P, Sie M, Ndjiondjop M, Drame NK, Traore K, Rodenburg J, Somado E, Narteh L, Youm O, Diagne A, Futakuchi K (2007). Exporting Partnerships in Research and Development to help African Rice Farmers cope with Climate Variability. An Open Access Journal published by ICRISAT pp. 1-24.

Mburu BK, Kung'u JB, Muriuki JN (2015). Climate change adaptation strategies by small-scale farmers in Yatta District, Kenya. African Journal of Environmental Science and Technology 9(9):712-722.

Ministry of Agriculture, MoA (2009). National Rice Development Strategy 2008-2018. KARI, Nairobi: Information and Documentation Services.

Muchiri LM (2013). Climate Change Impacts on Water Use Strategies in Mwea Irrigation Scheme, Kirinyaga County (Master's Thesis): Department of Environmental Education, Kenyatta University.

Ndiritu SW (2013). Essays on gender issues, food security, and technology adoption in East Africa. Goteborg, Sweden: University of Gothenburg. News.

Nguezet PM, Diagne A, Okoruwa V, Ojehomon V (2012). Estimation of actual and potential adoption rates and determinants of NERICA rice varieties in Nigeria. Journal of Crop Improvement 27(5).

National Irrigation Board (NIB) (2012). Annual report and accounts Nairobi: Kenya.

Nyamai M, Mati B, Home PG, Odongo B, Wanjogu R Thuranira EG (2012). Improving land and water productivity in basin rice cultivation in Kenya through system of rice intensification. Mwea Irrigation Agricultural Development Project. NIB, Kenya.

Olembo N, M'mboyi F, Oyugi K (2010). Success stories in crop improvement in Africa: The case of rice in Sub-Saharan Africa. Nairobi: African Biotechnology Stakeholders Forum.

Robert BW (2013). Managing Research. Maidenhead, England: Open University.

Spencer T, Liesel P (2012). Integrating food security into local government law, policy and planning: using local government legal structures to build community resilience to food insecurity. University of Western Sydney: U.S.A., Common Ground.

Speranza C (2010). Resilient Adaptation to Climate Change in African Agriculture. Bonn, Germany: German Development Institute.

Tuong TP (2009). Productive Water Use in Rice Production: Opportunities and Limitations. Journal of Crop Production 2(2). DOI: 10.1300/J144V02n02_10, 241-264.
United Nations Framework Convention on Climate Change (UNFCCC) (2006). UNFCCC newsletter. Bonn, Germany: United Nations Framework Convention on Climate Change.

U.S. Department of Agriculture (2017). Sub-Saharan Africa is projected to be the leader in global rice imports. https://www.ers.usda.gov/amber-waves/2017/october/sub-saharanafrica-is-projected-to-be-the-leader-in-global-rice-imports/

USAID (2017a) "Country Profile: Kenya." http://www.feedthefuture.gov/country/kenya

Uwaegbuonu O (2010). Determinants of adoption of new technologies. and the role of credit in the production of rice in Benue State, Nigeria. Agricultural Journal 5(4):264-268.

Wanjogu RK, Mugambi G, Adoli HL, Shisanya SO, Tamura M (1995). Mwea Rice Production Manual. Mwea Irrigation Agricultural Development Project.NIB, Kenya.

Yanagihara S, Kokusai N, Suisangyo A, Kenkyu S (2011). Next challenges in rice development for Africa: Workshop for new collaboration between JIRCAS and Africa Rice. Tsukuba: Japan International Research Centre for Agricultural Sciences. International Water Management Institute. 